\title{
The effect of $\mathrm{NaOCl}$ and heat treatment on static and dynamic mechanical properties and chemical changes of dentine
}

\author{
Karunanayake $\mathbf{G}^{1}$, Ng Y-L1, Knowles $\mathrm{JC}^{2,3,4}$, Delgado $\mathrm{AHS}^{2}$, Young $\mathrm{AM}^{2}$, \\ Gulabivala $\mathbf{K}^{1}$, Nazhat $\mathbf{S N}^{5}$ \\ 1 Unit of Endodontology, Divisions of Restorative Dental Science and \\ ${ }^{2}$ Biomaterials \& Tissue Engineering, UCL Eastman Dental Institute, University College London, London. \\ ${ }^{3}$ Institute of Tissue Regeneration Engineering (ITREN) and Department of \\ NanobiomedicalScience and BK21 Plus NBM, Global Research Center for Regenerative Medicine, \\ DankookUniversity, 518-10 Anseo-dong, Dongnam-gu, Cheonan, Chungcheongnam-do, Republic \\ ofKorea \\ ${ }^{4}$ The Discoveries Centre for Regenerative and Precision Medicine, UCL Campus, GowerStreet, \\ London WC1E 6BT, \\ ${ }^{5}$ Department of Mining and Materials Engineering, McGill University, Montreal, Qc, Canada. H3A 0C5.
}

\section{Running title: Effect of $\mathrm{NaOCl}$ and heat on dentine}

Key words: heat, flexural strength, storage modulus, maximum strain, tan delta.

To whom correspondence should be addressed:

$\operatorname{Dr} \mathrm{Y}-\mathrm{L} \mathrm{Ng}$

Unit of Endodontology,

UCL Eastman Dental Institute,

256 Grays Inn Road,

London WC1X 8LD,

United Kingdom

Tel: $\quad 02034561233$

Fax: $\quad 02034562371$

E-mail: $\quad$ y.ng@ucl.ac.uk 


\section{Abstract}

Objectives: To determine the effect of heat on flexural strength (FS), maximum strain (MS), storage modulus (SM), tan delta (TD) and chemical changes through micro-Raman spectroscopy of dentine exposed to $2.5 \% \mathrm{NaOCl}$ or saline.

Methodology: Dentine bars were randomly allocated to 8 test groups. Half (groups $2,4,6,8$ ) were treated with $\mathrm{NaOCl}$ for 20 mins; the rest (groups 1,3,5,7) remained in saline. FS/MS were measured in groups $1-4(n=15)\left(3 / 4\right.$ were also heated to $200^{\circ} \mathrm{C} \&$ re-hydrated in saline). Micro-Raman spectroscopy was performed on bars from groups 1-4. SM/TD were measured in 5-8: in 5/6 $(n=10)$, repeated after heating $\left(200^{\circ} \mathrm{C}\right)$, then following re-hydration; in $7 / 8(n=3)$ after heating to $25-185^{\circ} \mathrm{C}$.

Results: Increase in MS on heat and FS/MS on heat+ $\mathrm{NaOCl}$ was not significant $(P>0.05)$. SM increased $(P=0.06)$ after heat treatment but reduced to initial state after rehydration $(P=0.03)$. TD did not change $(P=0.4)$ after heat $\left(200^{\circ} \mathrm{C}\right)$ treatment but rehydration increased it compared with pre-treatment state $(\mathrm{P}=0.001)$. For dentine bars pre-treated with $\mathrm{NaOCl}$, SM did not change $(P=0.6)$ after heat $\left(200^{\circ} \mathrm{C}\right)$ treatment or rehydration but TD significantly increased $(P=0.02)$ upon re-hydration compared with pre- $(P=0.007)$, or post- $(P=0.03)$ heattreatment states. SM and TD varied between $25-185^{\circ} \mathrm{C}$ with no consistent trend amongst the $\mathrm{NaOCl}$ pre-treated bars. Micro-Raman only detected chemical changes following $\mathrm{NaOCl}$ treatment in the mineral phase.

Conclusions: Exposure of dentine bars to heat and $\mathrm{NaOCl}$ produced only moderate changes to quasi-static but marked changes to viscoelastic properties, which may be explained by chemical alterations. 


\section{Introduction}

The combination of mineral, organic and water components determine the mechanical behaviour of mineralised tissues (Gul-E-Noor et al., 2015; Unal and Akkus, 2015). Intracollagen fibrillar mineralisation provides elastic behaviour, whilst extra-fibrillar granular mineralisation, reinforced by inter-penetrating collagen fibrils, provides the viscous element when saturated with water (Kinney et al., 2003). Dentine dehydration may consolidate the granular mineral matrix by shrinkage of the interpenetrating collagen, thereby increasing Young's modulus.

Water in dentine resides in "bound" or "free" compartments; the latter within dentinal tubules $(75 \%)$ and former (25\%) within mineral and collagen phases (Gul-E-Noor et al., 2015; Unal and Akkus, 2015). Free water in tubules may contribute to resistance to occlusal forces by the work required to displace it upon compression (Granke et al., 2015; A. Kishen and Asundi, 2005; A. Kishen and Vedantam, 2007; Pashley, 1990), whilst bound-water contributes toughness, visco-elasticity and strength. Water molecules influence mechanical properties through formation of hydrogen bonds with various structural components in mineral as well as collagen (Gul-E-Noor et al., 2015). Free-water can be removed by heating dentine to $100{ }^{\circ} \mathrm{C}$ (Anil Kishen, 2006), whilst the bound water may be lost at temperatures above $200^{\circ} \mathrm{C}$ (Helfer et al., 1972; Anil Kishen, 2006).

The rigours of caries, tooth surface loss, wear and tear, age and loss of pulp vitality lead to a greater susceptibility of teeth to fracture in later life. This appears to be mediated by a combination of factors, including unfavourable changes in the architecture of the tooth due to dentine loss (Hansen and Asmussen, 1993; Mondelli et al., 1980; Reeh et al., 1989; Zelic et al., 2015), the mineral content of dentine (Nalla et al., 2003; Zelic et al., 2014), collagen cross-linking in dentin (Miura et al., 2014; Montoya et al., 2018; Yan et al., 2017) and pulpal proprioception (Bleicher, 2014; Byers and Cornel, 2018; Randow and Glantz, 1986). 
Root canal treatment may potentially further impose physical weakening of teeth (Gulabivala et al., 2005; Anil Kishen, 2006) through changes in the properties of dentine (Driscoll et al., 2002; Grigoratos et al., 2001; Rajasingham et al., 2010; Sim et al., 2001) caused by sodium hypochlorite $(\mathrm{NaOCl})$, EDTA or calcium hydroxide. $\mathrm{NaOCl}$ may unfavourably alter flexural strength and elastic modulus (Sim et al., 2001) of dentine and increase tooth surface strain (Rajasingham et al., 2010). The changes have been attributed to depletion and alteration of dentinal collagen by $\mathrm{NaOCl}$ (Driscoll et al., 2002; Morgan et al., 2018; Ramirez-Bommer et al., 2018). Despite these observations, $\mathrm{NaOCl}$ remains the first choice root canal disinfectant and has been adopted at concentrations ranging between $0.5 \%$ to $>5.0 \%$ (Dutner et al., 2012; Gulabivala et al., 2005; Koch et al., 2009). The most popular "compromiseconcentration" between antimicrobial or dissolution efficacy and potential harm to soft and hard tissues is $2.5 \%$ (Hommez et al., 2003), assuming a dose-dependent effect. The limitation of harm to dentine is also reliant upon the relatively superficial extent of effect on dentine (Morgan et al., 2018).

In addition, however, heat applied to dentine during or after root canal treatment, either deliberately (to soften gutta-percha) or inadvertently (during removal of gutta-percha, separated instruments or post-preparation) may through temperature increases of $200{ }^{\circ} \mathrm{C}$ cause damage to hydroxyapatite or collagen and dehydrate dentine (Lin et al., 2010). Dehydration makes dentine brittle (Hayashi et al., 2012; Huang et al., 1992; Jameson et al., 1993; A. Kishen and Asundi, 2005), although this change is reversible upon rehydration (Hayashi et al., 2012; Hayashi et al., 2010; Jameson et al., 1993). Hence the clinical impact of moisture loss may be transient because dentine may re-hydrate from surrounding fluids (Linden, 1968). Furthermore, dentine kept moist, is little affected in strength, when heated to $100^{\circ} \mathrm{C}$ (Rasmussen and Patchin, 1984).

The effect of heat on dentine may be mediated by altered collagen properties. Collagen, a key component of dentine, consisting of 3 helical polypeptide chains bound together by hydrogen and covalent bonds into a super-helix (Wang et al., 2002) undergoes various 
temperature-dependent and time-dependent changes (Suwa et al., 2016). Collagen structure is reportedly altered to different degrees at different temperatures $\left(20-200{ }^{\circ} \mathrm{C}\right)$ and levels of hydration and physical confinement (Armstrong et al., 2008; Gevorkian et al., 2013; Hayashi et al., 2012; Miles and Ghelashvili, 1999; Suwa et al., 2016; Vangsness et al., 1997; Wang et al., 2002). Collagen has been reported to denature at $200{ }^{\circ} \mathrm{C}$ (Yamashita et al., 2002).

It was hypothesised that heating dentine to $200{ }^{\circ} \mathrm{C}$ may denature or alter its constituent collagen and mineral content, as well as cause water loss, thus affecting its physical properties. Furthermore, $\mathrm{NaOCl}$ pre-treatment of dentine, could also theoretically deplete collagen, and this may either reduce the impact of heat compared to untreated dentine or exert an accumulative effect. The aim of this study was to investigate the effect of heat on dentine pre-treated with either $2.5 \%$ sodium hypochlorite or $0.9 \%$ saline; by assessing changes in its physical and chemical properties. 


\section{Material and Methods}

\subsection{Sample preparation and allocation to groups}

Ethical approval was granted for the use of extracted teeth from the UCL Eastman Biobank (Study number: 1301). Eighty-six standardized plano-parallel dentine bars of dimensions (2 $\mathrm{mm}$ depth $\times 0.6 \mathrm{~mm}$ height $x \geq 11 \mathrm{~mm}$ length) were cut exclusively from the roots of eightyfour extracted human teeth ( 25 molars, 49 premolars, 4 incisors and 8 canines stored in $4 \%$ formal-saline at room temperature (Jameson et al., 1993)) using a diamond saw (Exakt, $\mathrm{GmbH}$, Nordestedt, Germany) under a coolant water spray. The dentine bars were examined under magnification $(\times 3.2)$ (Global Surgical ${ }^{\mathrm{TM}}$ Microscope, St. Louis, USA) and discarded if they included cracks or parts of the root canal; the tubule direction was parallel to loading direction. The dentine bars were also stored in $4 \%$ formal-saline (Normasol, SSL, Oldham, UK) and randomly allocated to 8 test groups (Table 1). The randomization was stratified; ensuring that bars from each tooth type were distributed approximately evenly amongst the groups.

\subsection{Effect of $\mathrm{NaOCl}$ and heat treatment on flexural strength (Groups 1-4; $n=15$ each)}

Samples in groups 1 to 4 were exposed to $40 \mathrm{~mL}$ of $0.9 \%$ saline (Groups 1 \& 3 ) or $2.5 \%$ sodium hypochlorite solution (Teepol Bleach ${ }^{\circledR}$, Teepol products, Surrey, UK) (Groups $2 \& 4$ ), respectively, for 20 minutes. The concentration of sodium hypochlorite was verified by iodometric titration. Dentine bars in groups $1 \& 2$ were then stored in $0.9 \%$ saline solution without being subjected to heat treatment, whilst those in groups $3 \& 4$ were held for 10 minutes at $200{ }^{\circ} \mathrm{C}$ in a laboratory chamber furnace (Lenton, Hope Valley, UK), allowed to cool and replaced in $0.9 \%$ saline solution.

After exposure, the dentine bars were subjected to a 3-point bend-test using an Instron loading machine (Instron ${ }^{\circledR}$, High Wycombe, UK), with tubule orientation parallel to the loading, to measure the flexural strength (MPa) and maximum strain $(\%)$ of the dentine bars 
at fracture (Grigoratos et al. 2001). The cross-head diameter was $2.20 \mathrm{~mm}$ and the speed 1 $\mathrm{mm} / \mathrm{min}$.

\subsection{Effect of $\mathrm{NaOCl}$ and heat treatment (at $200^{\circ} \mathrm{C}$ ) on Storage Modulus and Tan Delta} (Groups 5 \& 6; $n=10$ each)

The dentine bars in groups 5 \& 6 were immersed in $40 \mathrm{~mL}$ of $0.9 \%$ saline or $2.5 \% \mathrm{NaOCl}$, respectively, for 20 minutes (Table 1). Following removal from their respective solutions, each dentine bar was left to partially air-dry, at room temperature for 10 minutes, whilst maintained on an electronic balance (Analytic balance, Denver instrument Company, Norfolk, UK). The rate of weight loss after 10 minutes (due to water loss) was found to be low and stable after this time. The final weight of the dentine bar was recorded.

Each bar was subsequently subjected to dynamic mechanical analysis (Ferry, 1980) to determine SM and TD (test 1); and then subjected to heat treatment at $200{ }^{\circ} \mathrm{C}$ for 10 minutes in a furnace (as previously described), allowed to cool and stored in a dry airtight storage container, and DMA repeated (test 2). The dentine bars were subsequently rehydrated in $0.9 \%$ saline for 24 hours and the DMA repeated once again (test 3 ).

\subsection{Effect of $\mathrm{NaOCl}$ and heat treatment on Tan Delta and Storage Modulus under conditions of dynamic temperature increase (Groups $7 \& 8$; $n=3$ each)}

Dentine bars in group $7 \& 8$ were immersed in $40 \mathrm{~mL}$ of $0.9 \%$ saline or exposed to $2.5 \%$ $\mathrm{NaOCl}$, respectively, for 20 minutes, left to partially air-dry, at room temperature for 10 minutes as previously described. Each dentine bar was then subjected to DMA under a continuous temperature scan at a starting ambient temperature of $18{ }^{\circ} \mathrm{C}$, increasing at a rate of $5{ }^{\circ} \mathrm{C}$ per minute and rising to a maximum temperature of $185^{\circ} \mathrm{C}$.

\subsection{Micro-Raman spectroscopy}

Three dentine bars randomly selected from groups $1,2,3$ and 4 were retained for microRaman analysis (LabRam 300, Horiba Jobin-Yvon, France). The samples were placed at a 
focus of a 50x microscope and three random point spectra were acquired at a resolution of $\sim 6 \mathrm{~cm}^{-1}$, over the spectral region of 850 to $1750 \mathrm{~cm}^{-1}$, with an accumulation time of $20 \mathrm{~s}$ and 3 acquisitions for each point. The resulting average spectra of each sample was gathered, processed using post processing tools (Labspec 5 software, Horiba Jobin-Yvon, Palaiseau, France) and peak intensities of the mineral phase and organic phase were averaged and the ratio between the two (mineral/organic) was calculated.

\subsection{Data analysis}

The data were analysed using the STATA® statistics/data analysis software version 13 (StataCorp, College Station, TX, USA). All inferential analysis was carried out at a significance level of $5 \%$.

General Linear Models were used to analyse the effects of $2.5 \% \mathrm{NaOCl}$ and heat treatment on the flexural strength (MPa) and maximum strain (\%) of the dentine bars in groups 1 to 4 .

Repeated measures ANOVA with pair-wise comparisons of marginal linear predictions were performed to compare values of tan delta and storage modulus (GPa) of dentine bars in groups 5 and 6, prior to heat treatment, after heat treatment and following re-hydration.

The storage modulus and tan delta values of dentine bars in groups 7 and 8 were plotted against the temperature and analysed descriptively.

The micro-Raman data were analysed by a two-way factorial ANOVA to compare the effect of the surface treatment $(\mathrm{NaOCl})$ and heat treatment on the mineral phase $\left(960 \mathrm{~cm}^{-1}\right)$, organic phase $\left(1667 \mathrm{~cm}^{-1}\right)$ and their ratio (Mineral/Collagen). All inferential analysis was carried out at a significance level of $5 \%$. 


\section{Results}

3.1 Effect of $\mathrm{NaOCl}$ and heat treatment on flexural strength and maximum strain at fracture (Groups 1-4; $n=15$ each group)

The mean values of flexural strength $(\mathrm{MPa})$ and maximum strain $(\%)$ at fracture for groups 1 to 4 are presented in Table 2. General linear model analysis revealed that chemical $(\mathrm{NaOCl}$ or saline) $(\mathrm{P}=0.8, \mathrm{P}=0.2)$ or heat (room temperature or $\left.200^{\circ} \mathrm{C}\right)(\mathrm{P}=0.7, \mathrm{P}=0.07)$ treatment individually had no statistically significant effect on the flexural strength or maximum strain at fracture of the dentine bars at the $5 \%$ level, respectively.

\subsection{Effect of $\mathrm{NaOCl}$ and heat treatment (at $200^{\circ} \mathrm{C}$ ) on Storage Modulus and Tan Delta} (Groups $5 \&$ 6; $n=10$ each)

Data for the effect of heat and re-hydration on storage modulus and tan delta of dentine bars, with or without $\mathrm{NaOCl}$ pre-treatment, are presented in Table 3.

\subsubsection{Group 5 (Saline)}

Two dentine bars fractured during testing, reducing the sample size to 8 . The repeated ANOVA revealed that the heat treatment and subsequent rehydration did not have a significant effect on storage modulus $(\mathrm{GPa})(\mathrm{P}=0.06)$, but a significant effect on tan delta $(\mathrm{P}=0.0002)$ at the $5 \%$ level. Post hoc pairwise comparison of marginal linear predictions revealed an increase in storage modulus after the heat treatment $(P=0.06)$ with a significant subsequent reduction after rehydration $(P=0.03)$ returning to the pre-treatment state $(P=0.7)$. There was no significant change in tan delta after heat treatment $(P=0.4)$ but the subsequent rehydration resulted in a highly significant increase in tan delta compared with the pretreatment state $(P=0.001)$ or after heat treatment $(P<0.0001)$.

\subsubsection{Group $6(2.5 \% \mathrm{NaOCl})$}

Amongst the dentine specimens pre-treated with $\mathrm{NaOCl}$, subsequent heat treatment and rehydration had no significant effect on storage modulus $(P=0.6)$ but significant effects on tan delta $(\mathrm{P}=0.02)$ (Table 3$)$. Post hoc pairwise comparisons of marginal linear predictions 
revealed there were no significant changes in the tan delta after heat treatment $(P=0.5)$; however, the subsequent re-hydration resulted in significant increase in tan delta compared with the pre- $(P=0.007)$, or post- $(P=0.03)$ heat-treatment states.

\subsection{Effect of $\mathrm{NaOCl}$ and heat treatment on Tan Delta and Storage Modulus under conditions of dynamic temperature increase (Groups $7 \& 8 ; n=3$ each)}

\subsubsection{Group 7 (Saline)}

The changes in storage modulus and tan delta with temperature amongst the three bars followed a similar trend. The plots of storage modulus and tan delta against temperature of a representative dentine bar are presented in Figure 1. It shows a change in storage modulus and tan delta with temperature increase. The storage modulus initially fell in value from 25$60{ }^{\circ} \mathrm{C}$ and then increased linearly in value, reaching a plateau around $143-170{ }^{\circ} \mathrm{C}$, followed by a further drop. In contrast, tan delta values showed an inverse trend with values increasing up to temperatures of $80-100{ }^{\circ} \mathrm{C}$, after which they fell at around $118^{\circ} \mathrm{C}$, followed by an increase to values above the baseline. The two plots intersected at around $100{ }^{\circ} \mathrm{C}$ for all three bars.

\subsubsection{Group $8(2.5 \% \mathrm{NaOCl})$}

The changes in storage modulus and tan delta with temperature amongst the three dentine bars pre-treated with $\mathrm{NaOCl}$ did not follow similar trends and hence are all presented (Figures 2 a-c).

The storage modulus of dentine bars $1 \& 2$ increased with temperature but with fluctuation in dentine bar 1 and plateauing at $120^{\circ} \mathrm{C}$ in dentine bar 2 . The storage modulus of dentine bar 3 fluctuated throughout, with a sharp peak at $40^{\circ} \mathrm{C}$ and a smooth peak at $110^{\circ} \mathrm{C}$.

Tan delta values showed unpredictable variation in pattern that was different to that observed in dentine bars not exposed to $\mathrm{NaOCl}$. In dentine bar 1 , there was a small decrease in tan delta between $25-60{ }^{\circ} \mathrm{C}$, and the values fluctuated thereafter until it 
increased steeply after $160^{\circ} \mathrm{C}$. In dentine bar 2 , there was small fluctuation in the tan delta values with peaks at around $65{ }^{\circ} \mathrm{C}$ and $115^{\circ} \mathrm{C}$. In dentine bar 3 , the tan delta values increased with a peak at $70^{\circ} \mathrm{C}$ and then decreased thereafter. Regardless of the variations, tan delta values increased above the baseline values when $185^{\circ} \mathrm{C}$ was reached.

\subsection{Micro-Raman spectroscopy}

The Raman spectra of the selected dentine bars from groups 1-4 are shown in Figure 3 . The region below $1100 \mathrm{~cm}^{1}$ in dentine spectra represent phosphate $\left(960 \mathrm{~cm}^{-1}\right)$ and carbonate groups $\left(1072 \mathrm{~cm}^{-1}\right)$. The organic phase, representing collagen includes (amide I $1667 \mathrm{~cm}^{-1}$, amide III $1243 \mathrm{~cm}^{-1}$ and $\mathrm{CH}_{2}$ deformation at $1457 \mathrm{~cm}^{-1}$ ). Saline with no heat gave the baseline spectra.

Application of $\mathrm{NaOCl}$ resulted in depletion of the $1667 \mathrm{~cm}^{-1}$ peak and increase in the 1072 $\mathrm{cm}^{-1}$ peak (Table 4). The minor changes reflected in the mean differences between groups considering the mineral and organic phases alone were not statistically significant $(P>0.05)$. However, the interaction between the two factors (surface treatment vs. heat treatment) was statistically significant $(P=0.04)$ when the hydroxyapatite $(H A)$ peak was taken into account: Heat treatment resulted in depletion of HA peak in samples exposed to saline but increase in HA peak amongst samples exposed to $\mathrm{NaOCl}$. The only statistically significant difference $(P=0.04)$ lay in the carbonate peak, which increased following the application of $\mathrm{NaOCl}$. 


\section{Discussion}

The reported Young's modulus values for dentine vary enormously, the likely true estimated value is said to lie between 18-20 GPa (Kinney et al., 2003). The variations are attributed to specimen preparation and flaws (Ryou et al., 2011), experimental design, stress relaxation, and storage conditions (Kinney et al., 2003). Dentine bar preparation and their dimensions could affect their mechanical properties (Grigoratos et al., 2001; Sim et al., 2001) but the consistency in values within previous and current study suggests this was relatively well controlled. Any limited size discrepancy between samples was accounted for by individual measurement of samples.

Dentine properties may also differ by location within the source teeth; Ryou et al., (2011) reported significantly lower elastic modulus, strength and energy to fracture in dentine harvested near the pulp than that harvested superficially. Bars of larger dimensions would therefore exhibit heterogeneous properties or property gradients. Additionally, intertubular dentine heated to $140{ }^{\circ} \mathrm{C}$ has been shown to be affected more than peritubular dentine (Hayashi et al., 2012), suggesting an influence mediated to a greater extent by changes to collagen.

Dentine is moderately anisotropic by virtue of its tubular structure and in a perpendicular direction due to its intertubular collagen matrix (Kinney et al., 2003), particularly in the context of heated dentine $\left(140{ }^{\circ} \mathrm{C}\right)$ (Hayashi et al., 2008). The tubular structure does not cause anisotropy relative to its elastic properties (Kinney et al., 1999) but tensile strength was deemed lowest when aligned with the tubules (Hayashi et al., 2008; Ryou et al., 2011). The DMA and Instron tests in this study would be deemed to have been performed in the plane of maximum strength - parallel to the dentinal tubules (Forien et al., 2015; Kinney et al., 2003; Anil Kishen, 2006; Nalla et al., 2003; Zaslansky et al., 2016). Hayashi et al. (2008) found that flexural and microtensile strength in specimens with tubules oriented parallel to the load were $2-2.4 \times$ higher after heating to $140{ }^{\circ} \mathrm{C}$ for 1 hour but heating to $200{ }^{\circ} \mathrm{C}$ reduced 
the flexural $\left(178 \mathrm{MPa}\right.$ at $140{ }^{\circ} \mathrm{C} ; 145 \mathrm{MPa}$ at $\left.200{ }^{\circ} \mathrm{C}\right)$ and microtensile $\left(195 \mathrm{MPa}\right.$ at $140{ }^{\circ} \mathrm{C}$; $167 \mathrm{MPa}$ at $200^{\circ} \mathrm{C}$ ) strength.

The present study revealed that chemical or heat treatment individually had no significant effect on flexural strength or maximum strain at fracture of the dentine bars at the $5 \%$ level. This would seem consistent with Hayashi et al. (2008). The interactive effects of chemical and heat treatments on both flexural strength $(P=0.06)$ and maximum strain at fracture $(P=0.08)$, were not significant at the $5 \%$ level, suggesting minimal accumulative effect and possibility of mediation via changes to both collagen and hydroxyapatite.

The outcome of FS related to $\mathrm{NaOCl}$ treatment contrasts with the findings of Grigoratos et al., (2001) and Sim et al., (2001), in the level of statistical certainty. In Grigoratos et al., (2001), exposure of dentine bars $(11.7 \times 1.0 \times 1.0 \mathrm{~mm})$ to $3 \% \mathrm{NaOCl}$ significantly reduced flexural strength (from $8.7 \times 10^{7} \mathrm{~Pa}$ [for saline] to $3.7 \times 10^{7} \mathrm{~Pa}$ ). Whilst in Sim et al., (2001), exposure of dentine bars $(11.7 \times 0.8 \times 0.8 \mathrm{~mm})$ to $0.5 \% \mathrm{NaOCl}$ did not reduce flexural strength, whereas exposure to $5 \% \mathrm{NaOCl}$ did $\left(17 \times 10^{7} \mathrm{~Pa}\right.$ vs $\left.10.3 \times 10^{7} \mathrm{~Pa}\right)$. Dentine tubule orientation to the applied force was the same as in the present study. The differences in outcomes may reflect different sample parameters or test conditions; possibly a dose-dependent effect, $2.5 \%$ lying between the virtual absence of effect at $0.5 \%$ (Sim et al., 2001) and manifest effect at 3.0\% (Grigoratos et al., 2001). Nevertheless, the direction of effect is consistent and explainable by collagen denaturation at the dentine surface (Ramirez-Bommer et al., 2018). Strength and elasticity are largely contributed to by the mineral structure, which should be minimally affected by $\mathrm{NaOCl}$, except possibly at the surface.

The Raman spectra in this study (Figure 3) showed slight changes in the intensity of peaks, reflecting alteration in the chemistry of the dentine substrate. The mineral/collagen ratio (ratio between the $960 \mathrm{~cm}^{-1}$ peak for hydroxyapatite and $1667 \mathrm{~cm}^{-1}$ for amide I) was increased in samples subjected to $2.5 \% \mathrm{NaOCl}$ alone and followed by heat treatment, revealing the organic phase of the substrate shows initial depletion, however, these changes 
were not statistically significant compared to the controls. These observations are consistent with the mechanical findings and in accordance with Pascon et al., (2012), since in their study pretreatment with $5.25 \% \mathrm{NaOCl}$ (a higher concentration) did not alter, significantly, the organic content of permanent dentine as confirmed by micro-Raman analysis. The collagen is surrounded and protected by the mineral phase, this may explain why no marked changes were evident (Miles and Ghelashvili, 1999). The increase in the carbonate peak $\left(\mathrm{CO}_{3}\right.$ at $1072 \mathrm{~cm}^{-1}$ ) in this study, however, was statistically significant and is consistent with the formation of carbonate, known to occur due to treatment with $\mathrm{NaOCl}$ as previously reported (Tsuda et al., 1996). As carbonate content increases, there is a resulting decrease in crystallinity which in turn is known to affect mechanical properties (Xu et al., 2012). However, in the current study, no significant change in FS was observed after exposure to $2.5 \%$ $\mathrm{NaOCl}$, regardless of heat treatment, suggesting the chemical changes that did occur were mainly a surface effect (Morgan et al., 2018; Ramirez-Bommer et al., 2018).

The effect of heat on the quasi-static test outcomes on dentine reveals a range of effects, depending upon the source of the sample, test method and property under test (Lin et al., 2010).

The present findings contrast with those of Watts et al., (1987) who showed when testing dentine loaded perpendicular to tubules that Young's modulus, proportional limit, compressive strength and resilience all linearly decreased with increasing temperature $(0-80$ $\left.{ }^{\circ} \mathrm{C}\right)$. The toughness decreased from $0{ }^{\circ} \mathrm{C}$ to $37^{\circ} \mathrm{C}$ and then remained constant up to $80{ }^{\circ} \mathrm{C}$. Whilst, Rees et al., (1994) also using DMA, found an increase in Young's modulus with temperature $\left(27^{\circ} \mathrm{C}-37^{\circ} \mathrm{C}\right)$; the authors postulating that the effect may be due to dessication. The effect on flexural strength and maximum strain at fracture in the present study may be attributed to some initial denaturation of collagen and in the case of effect of heat, in addition the loss of bound water from the inter-tubular matrix and may also be due to changes in the mineral composition, with the increase of carbonate. 
In the present study, when dentine specimens were pre-treated with $\mathrm{NaOCl}$, heat treatment and rehydration had no significant effect on storage modulus $(P=0.6)$ but significant effects on tan delta $(P=0.02)$. There were no changes in tan delta after heat treatment $(P=0.5)$ but there was a significant increase in tan delta upon rehydration compared with the pre$(P=0.007)$, or post- $(P=0.03)$ heat-treatment states.

The results of groups 7 and 8 confirmed the outcomes in groups 5 and 6 but conveyed interesting insight into variations leading up to the final outcomes evident in the latter groups. They showed variation in the storage modulus and tan delta values with changing ambient temperature. The patterns of change in group 7 compared with group 8 were starkly different. In the saline-exposed specimens of group 7, the data for the 3 bars consistently showed a decrease in storage modulus between $25-50{ }^{\circ} \mathrm{C}$, followed by a subsequent rise between $50-140{ }^{\circ} \mathrm{C}$. In the same temperature ranges, tan delta showed a mirror image increase and then decrease. Between the temperatures of $100-145{ }^{\circ} \mathrm{C}$, the trend was reversed with storage modulus increasing, whilst tan delta continued to decrease upto 115 ${ }^{\circ} \mathrm{C}$ and thereafter slowly increasing. Between $145-185{ }^{\circ} \mathrm{C}$, storage modulus decreased, whilst tan delta continued its increase to converge with storage modulus at $185^{\circ} \mathrm{C}$. It was speculated that the dentinal collagen was becoming more flexible with the rise in temperature, thus accounting for the fall in storage modulus as the temperature rose to 60 ${ }^{\circ} \mathrm{C}$. However above $60^{\circ} \mathrm{C}$, collagen shrinkage (Vangsness et al., 1997) may have caused stiffening until at $145{ }^{\circ} \mathrm{C}$, collagen dehydration probably limited further increase and led to a decline.

The behaviour of dentine bars pre-treated with sodium hypochlorite (Group 8) was starkly different and showed variation in pattern and actual values amongst the 3 bars. The inverse relationship between storage modulus and tan delta (in Group 7) was less evident. Storage modulus showed an increase in two bars and a slight decrease in one. Tan delta showed variations that were similar in pattern in bars 2 and 3 but different in the first. The variations 
may be accounted for by differences in collagen depletion between the 3 bars, which in turn may also reflect anatomical differences in the dentine.

Given the close conjunction of collagen and apatite in dentine, there are likely to be mechanical interactions between these two components with chemical or thermal alterations playing a part in any altered physical properties of the composite. The effect of heat on natural composites containing organic and inorganic components has been studied in various tissue types. Heating a native collagen fibril reduced its Young's modulus at temperatures between $20-58{ }^{\circ} \mathrm{C}$, due to partial denaturation of triple helices; but it then remained constant between $58-75^{\circ} \mathrm{C}$ because of stabilization by inter-molecular interactions when hydrated. This stabilization phase was associated with absorption of water under heating, which was deemed to be due to restructuring of the triple helices (Gevorkian et al., 2013). The thermal stability of collagen depends on resistance to unfolding as a result of heat (Armstrong et al., 2008). The unfolding occurs first by separation of triple helices into individual helices due to disruption of hydrogen bonds between the polypeptide chains. Individual helices may then unfold into random coils due to disruption of intra-helical hydrogen bonds. As water is lost, the collagen fibrils are said to approximate, allowing collagen peptides to form new intrinsic associations due to hydrogen bonds in addition to covalent intermolecular cross-links critical to the stability of the triple helices. The new hydrogen bonds stiffen and strengthen the collagen matrix making it more stable to elevations in temperature in the absence of water. When rehydrated, there is a rapid loss in stiffness, indicating that the changes are reversible and due to weak non-covalent forces. In addition, hydration is enhanced by unfolded collagen in the presence of water (McGee et al., 2012). Thermal denaturation of collagen may occur to different levels at $65{ }^{\circ} \mathrm{C}$ and $150{ }^{\circ} \mathrm{C}$ under hydration but continue at $220^{\circ} \mathrm{C}, 305^{\circ} \mathrm{C}$, and $345^{\circ} \mathrm{C}$ when dry (Bozec and Odlyha, 2011). Denaturation of collagen fibrils is dependent on water hydration, temperature and duration for which it is held at that temperature. One minute at temperatures higher than 80 ${ }^{\circ} \mathrm{C}$ in water may achieve collagen fibril denaturation, whilst fibrils in water held at 
temperatures of $80{ }^{\circ} \mathrm{C}$ for only 1 min achieved partial denaturation, complete denaturation taking 90 mins. In dry conditions, fibrils maintain their native structure even after heating to $120{ }^{\circ} \mathrm{C}$ for 90 mins, although partial denaturation could not be prevented (Suwa et al., 2016).

Heating collagen in tendons caused it to shrink by $10 \%$ and reduced its load to failure by $33 \%$ (Vangsness et al., 1997). When confined within bone, heat-induced unwinding of collagen molecules could alter bone stiffness; the same effect but to a lesser degree could be induced by enzyme denaturation of collagen (Wang et al., 2002). Both types of collagen denaturation caused similar changes in strength and work to fracture in bone.

When collagen is confined within the mineralized structure of dentine, the collagen in its natural state is thought to be under tension, whilst the attached intrafibrillar apatite nanoparticles are in compression (Forien et al., 2015; Zaslansky et al., 2016). Furthermore, as explained above, confinement of the collagen in a mineral matrix may stabilize it to thermal denaturation by the so-called "polymer-in-a-box" phenomenon (Miles and Ghelashvili, 1999). Taking these two phenomena into account, heating dentine to $200{ }^{\circ} \mathrm{C}$ may still have a denaturing effect on the collagen throughout the bulk of the specimen, possibly drawing the mineral together and causing stiffening. Rehydration may soften the collagen components and reduce the stiffness, explaining the findings on the quasi-static properties in this study.

The effect of $\mathrm{NaOCl}$ on surface degradation of collagen would be to alter the state of balance of compressive and tensile forces within dentine to the depth of its chemical effect. This may have a marginal effect on flexural strength and increase the maximum strain before fracture as the material in the outer boundaries would be less tightly interwoven by the collagen mesh.

Similarly, the observations for storage modulus with saline pre-treatment contrast with $\mathrm{NaOCl}$ treatment and may be explained by the effect of $\mathrm{NaOCl}$ on the collagen component. Presumably, degradation of the collagen component deprives the structure of the build-up in 
stresses created by shrinkage in the saline treatment group. The effect on tan delta is as expected given that partially degraded and denatured collagen would still attract hydration (McGee et al., 2012) and increased viscous behaviour.

Yamashita et al., (2002) assessed the viscoelasticity of bone heated to $100{ }^{\circ} \mathrm{C}$ or $200{ }^{\circ} \mathrm{C}$ with DMA; half the specimens were rehydrated after heat treatment, whilst the other half were tested dry. Significant collagen denaturation only occurred when bone was heated to $200{ }^{\circ} \mathrm{C}$, irrespective of hydration; the percentage of denatured collagen did not show a significant effect on tan delta but higher $\tan \delta$ values were observed in wet samples compared to dry. They concluded that hydration condition rather than denatured collagen affected tan delta, whilst storage modulus was not strongly affected either by percentage of denatured collagen or by water content. In this respect, the present study differed because a significant increase in storage modulus $(P=0.06)$ was found upon heating to $200{ }^{\circ} \mathrm{C}$ that was restored upon rehydration $(P=0.03)$, returning to the pre-treatment state $(P=0.7)$. Simultaneously, there was no change in tan delta after heat treatment $(P=0.4)$ but subsequent rehydration significantly increased tan delta in comparison to the pre-treatment state $(P=0.001)$ or after heat treatment $(P<0.0001)$. The differences could be explained at least partly by the differences in degree of confinement of the collagen fibres in the two tissue types. The effect of heat may be to drive out the free and bound water from the dentine leading to shrinkage of both the collagen and apatite nanoparticles, causing a "tightening" and consolidation of the structure to make it stiffer and elastic. Restoration of the hydrated status would then return the mineral and organic components to their normal structure and hence physical properties (Forien et al., 2016). Denatured collagen may draw greater water saturation resulting in higher viscous tendency (McGee et al., 2012).

In summary, heat has an effect on the chemical and mechanical properties and physical behaviour of dentine, the extent of which may be dependent on the type of dentine and the relative exposure of the bulk material to heat and/or $\mathrm{NaOCl}$. Clinically, this implies that caution should be exercised in the extent of exposure to heat and on the application of 
forces, particularly whilst dentine is in a dehydrated or semi-hydrated state immediately after heat application.

\section{Conclusions}

Within the limitations of this study it may be concluded that exposure of dentine bars to heat and $\mathrm{NaOCl}$, independently and accumulatively, produced moderate changes in quasi-static mechanical properties but more obvious and marked changes in viscoelastic properties. These may be explainable by chemical changes in collagen. 


\section{List of tables}

Table 1 - The test groups, chemical, heat treatments and physical tests

Table 2 - Mean ( $\pm S D$ ) flexural strength and maximum strain of dentine bars in groups 1-4 and the effects of sodium hypochlorite, and heat treatment

Table 3 - Mean $( \pm S D)$ storage modulus and tan delta of dentine bars in groups $5 \& 6$, before heat treatment, after heat treatment and following rehydration in the saline (NB. Two bars in the saline group fractured during testing).

Table 4 - Table with micro-Raman intensity means $( \pm S D)$ for groups $1-4$ and the effects of heat and $\mathrm{NaOCl}$ treatment on the apatite, carbonate, collagen peak intensity or ratio of mineral/collagen intensity.

\section{List of figures}

Figure 1 - Changes in storage modulus and tan delta with temperature increase; saline group.

Figure 2 - Changes in storage modulus and tan delta with temperature increase; sodium hypochlorite group.

Figure 3 - Micro-Raman spectra of dentine from groups 1- 4 (800-1750 $\mathrm{cm}^{-1}$ region). 


\section{References}

Armstrong, S. R., Jessop, J. L., Winn, E., Tay, F. R., \& Pashley, D. H., 2008. Effects of polar solvents and adhesive resin on the denaturation temperatures of demineralised dentine matrices. J. Dent. 36, 8-14.

Bleicher, F., 2014. Odontoblast physiology. Exp. Cell Res. 325, 65-71.

Bozec, L., \& Odlyha, M., 2011. Thermal denaturation studies of collagen by microthermal analysis and atomic force microscopy. Biophys. J. 101, 228-236.

Byers, M. R., \& Cornel, L. M., 2018. Multiple complex somatosensory systems in mature rat molars defined by immunohistochemistry. Arch. Oral. Biol. 85, 84-97.

Driscoll, C. O., Dowker, S. E., Anderson, P., Wilson, R. M., \& Gulabivala, K., 2002. Effects of sodium hypochlorite solution on root dentine composition. J. Mater. Sci. Mater. Med. 13, 219-223.

Dutner, J., Mines, P., \& Anderson, A., 2012. Irrigation trends among American Association of Endodontists members: a web-based survey. J. Endod. 38, 37-40.

Ferry, J. D. (1980). Viscoelastic properties of polymers: John Wiley \& Sons.

Forien, J.-B., Fleck, C., Cloetens, P., Duda, G., Fratzl, P., Zolotoyabko, E., \& Zaslansky, P., 2015. Compressive residual strains in mineral nanoparticles as a possible origin of enhanced crack resistance in human tooth dentin. Nano letters 15, 3729-3734.

Forien, J.-B., Zizak, I., Fleck, C., Petersen, A., Fratzl, P., Zolotoyabko, E., \& Zaslansky, P., 2016. Water-mediated collagen and mineral nanoparticle interactions guide functional deformation of human tooth dentin. Chemistry of Materials 28, 3416-3427.

Gevorkian, S. G., Allahverdyan, A. E., Gevorgyan, D. S., Simonian, A. L., \& Hu, C.-K., 2013. Stabilization and anomalous hydration of collagen fibril under heating. PloS one 8 , e78526.

Granke, M., Does, M. D., \& Nyman, J. S., 2015. The Role of Water Compartments in the Material Properties of Cortical Bone. Calcif. Tissue Int. 97, 292-307.

Grigoratos, D., Knowles, J., Ng, Y. L., \& Gulabivala, K., 2001. Effect of exposing dentine to sodium hypochlorite and calcium hydroxide on its flexural strength and elastic modulus. Int. Endod. J. 34, 113-119.

Gul-E-Noor, F., Singh, C., Papaioannou, A., Sinha, N., \& Boutis, G. S., 2015. Behavior of water in collagen and hydroxyapatite sites of cortical bone: fracture, mechanical wear, and load bearing studies. The Journal of Physical Chemistry C 119, 2152821537.

Gulabivala, K., Patel, B., Evans, G., \& Ng, Y. L., 2005. Effects of mechanical and chemical procedures on root canal surfaces. Endodontic Topics 10, 103-122.

Hansen, E. K., \& Asmussen, E., 1993. Cusp fracture of endodontically treated posterior teeth restored with amalgam. Teeth restored in Denmark before 1975 versus after 1979. Acta. Odontol. Scand. 51, 73-77.

Hayashi, M., Furuya, Y., Minoshima, K., Saito, M., Marumo, K., Nakashima, S., . . Ebisu, S., 2012. Effects of heating on the mechanical and chemical properties of human dentin. Dent. Mater. 28, 385-391.

Hayashi, M., Koychev, E. V., Okamura, K., Sugeta, A., Hongo, C., Okuyama, K., \& Ebisu, S., 2008. Heat treatment strengthens human dentin. J. Dent. Res. 87, 762-766.

Hayashi, M., Okamura, K., Koychev, E. V., Furuya, Y., Sugeta, A., Ota, T., \& Ebisu, S., 2010. Effects of rehydration on dentin strengthened by heating or UV irradiation. J. Dent. Res. 89, 154-158.

Helfer, A. R., Melnick, S., \& Schilder, H., 1972. Determination of the moisture content of vital and pulpless teeth. Oral. Surg. Oral. Med. Oral. Pathol. 34, 661-670.

Hommez, G. M., Braem, M., \& De Moor, R. J., 2003. Root canal treatment performed by Flemish dentists. Part 1. Cleaning and shaping. Int. Endod. J. 36, 166-173.

Huang, T. J., Schilder, H., \& Nathanson, D., 1992. Effects of moisture content and endodontic treatment on some mechanical properties of human dentin. J. Endod. 18, 209-215. 
Jameson, M. W., Hood, J. A., \& Tidmarsh, B. G., 1993. The effects of dehydration and rehydration on some mechanical properties of human dentine. J. Biomech. 26, 10551065.

Kinney, J. H., Balooch, M., Marshall, G. W., \& Marshall, S. J., 1999. A micromechanics model of the elastic properties of human dentine. Arch. Oral Biol. 44, 813-822.

Kinney, J. H., Marshall, S. J., \& Marshall, G. W., 2003. The mechanical properties of human dentin: a critical review and re-evaluation of the dental literature. Crit. Rev. Oral Biol. Med. 14, 13-29.

Kishen, A., 2006. Mechanisms and risk factors for fracture predilection in endodontically treated teeth. Endodontic Topics 13, 57-83.

Kishen, A., \& Asundi, A., 2005. Experimental investigation on the role of water in the mechanical behavior of structural dentine. J. Biomed. Mater. Res. A 73, 192-200.

Kishen, A., \& Vedantam, S., 2007. Hydromechanics in dentine: role of dentinal tubules and hydrostatic pressure on mechanical stress-strain distribution. Dent. Mater. 23, 12961306.

Koch, M., Eriksson, H. G., Axelsson, S., \& Tegelberg, A., 2009. Effect of educational intervention on adoption of new endodontic technology by general dental practitioners: a questionnaire survey. Int. Endod. J. 42, 313-321.

Lin, M., Xu, F., Lu, T. J., \& Bai, B. F., 2010. A review of heat transfer in human tooth-experimental characterization and mathematical modeling. Dent. Mater. 26, 501-513.

Linden, L. A., 1968. Microscopic observations of fluid flow through cementum and dentine. An in vitro study on human teeth. Odontol. Revy. 19, 367-381.

McGee, M. P., Morykwas, M., Shelton, J., \& Argenta, L., 2012. Collagen unfolding accelerates water influx, determining hydration in the interstitial matrix. Biophys.. $J$ 103, 2157-2166.

Miles, C. A., \& Ghelashvili, M., 1999. Polymer-in-a-box mechanism for the thermal stabilization of collagen molecules in fibers. Biophys. J. 76, 3243-3252.

Miura, J., Nishikawa, K., Kubo, M., Fukushima, S., Hashimoto, M., Takeshige, F., \& Araki, T., 2014. Accumulation of advanced glycation end-products in human dentine. Arch. Oral Biol. 59, 119-124.

Mondelli, J., Steagall, L., Ishikiriama, A., de Lima Navarro, M. F., \& Soares, F. B., 1980. Fracture strength of human teeth with cavity preparations. J. Prosthet. Dent. 43, 419422.

Montoya, C., Arola, D., \& Ossa, E. A., 2018. Deformation behaviour of aged coronal dentin. Gerodontology 35, 95-100.

Morgan, A. D., Ng, Y. L., Odlyha, M., Gulabivala, K., \& Bozec, L., 2019. Proof-of-concept study to establish an in situ method to determine the nature and depth of collagen changes in dentine using Fourier Transform Infra-Red spectroscopy after sodium hypochlorite irrigation. Int. Endod. J. 52, 359-370.

Nalla, R. K., Kinney, J. H., \& Ritchie, R. O., 2003. Effect of orientation on the in vitro fracture toughness of dentin: the role of toughening mechanisms. Biomaterials 24, 39553968.

Pascon, F. M., Kantovitz, K. R., Soares, L. E., Santo, A. M., Martin, A. A., \& Puppin-Rontani, R. M., 2012. Morphological and chemical changes in dentin after using endodontic agents: fourier transform Raman spectroscopy, energy-dispersive $\mathrm{x}$-ray fluorescence spectrometry, and scanning electron microscopy study. J. Biomed. Opt. 17, 075008.

Pashley, D. H. (1990). Dentin permeability. In L. S. Spangberg (Ed.), Experimental endodontics (pp. 19-49): CRC Press.

Rajasingham, R., Ng, Y. L., Knowles, J. C., \& Gulabivala, K., 2010. The effect of sodium hypochlorite and ethylenediaminetetraacetic acid irrigation, individually and in alternation, on tooth surface strain. Int. Endod. J. 43, 31-40.

Ramirez-Bommer, C., Gulabivala, K., Ng, Y. L., \& Young, A., 2018. Estimated depth of apatite and collagen degradation in human dentine by sequential exposure to sodium hypochlorite and EDTA: a quantitative FTIR study. Int. Endod. J. 51, 469-478. 
Randow, K., \& Glantz, P. O., 1986. On cantilever loading of vital and non-vital teeth. An experimental clinical study. Acta. Odontol. Scand. 44, 271-277.

Rasmussen, S. T., \& Patchin, R. E., 1984. Fracture properties of human enamel and dentin in an aqueous environment. J. Dent. Res. 63, 1362-1368.

Reeh, E. S., Messer, H. H., \& Douglas, W. H., 1989. Reduction in tooth stiffness as a result of endodontic and restorative procedures. J. Endod. 15, 512-516.

Rees, J. S., Jacobsen, P. H., \& Hickman, J., 1994. The elastic modulus of dentine determined by static and dynamic methods. Clin. Mater. 17, 11-15.

Ryou, H., Amin, N., Ross, A., Eidelman, N., Wang, D. H., Romberg, E., \& Arola, D., 2011. Contributions of microstructure and chemical composition to the mechanical properties of dentin. J. Mater. Sci. Mater. Med. 22, 1127-1135.

Sim, T. P., Knowles, J. C., Ng, Y. L., Shelton, J., \& Gulabivala, K., 2001. Effect of sodium hypochlorite on mechanical properties of dentine and tooth surface strain. Int. Endod. J. 34, 120-132.

Suwa, Y., Nam, K., Ozeki, K., Kimura, T., Kishida, A., \& Masuzawa, T., 2016. Thermal denaturation behavior of collagen fibrils in wet and dry environment. J. Biomed. Mater. Res. B Appl. Biomater. 104, 538-545.

Tsuda, H., Ruben, J., \& Arends, J., 1996. Raman spectra of human dentin mineral. Eur. J. Oral Sci. 104, 123-131.

Unal, M., \& Akkus, O., 2015. Raman spectral classification of mineral- and collagen-bound water's associations to elastic and post-yield mechanical properties of cortical bone. Bone 81, 315-326.

Vangsness, C. T., Jr., Mitchell, W., 3rd, Nimni, M., Erlich, M., Saadat, V., \& Schmotzer, H., 1997. Collagen shortening. An experimental approach with heat. Clin. Orthop. Relat. Res. 337, 267-271.

Wang, X., Li, X., Bank, R. A., \& Agrawal, C. M., 2002. Effects of collagen unwinding and cleavage on the mechanical integrity of the collagen network in bone. Calcif. Tissue Int. 71, 186-192.

Watts, D. C., el Mowafy, O. M., \& Grant, A. A., 1987. Temperature-dependence of compressive properties of human dentin. J. Dent. Res. 66, 29-32.

Xu, C., Reed, R., Gorski, J. P., Wang, Y., \& Walker, M. P., 2012. The Distribution of Carbonate in Enamel and its Correlation with Structure and Mechanical Properties. J. Mater. Sci. 47, 8035-8043.

Yamashita, J., Li, X., Furman, B. R., Rawls, H. R., Wang, X., \& Agrawal, C. M., 2002. Collagen and bone viscoelasticity: a dynamic mechanical analysis. J. Biomed. Mater. Res. 63, 31-36.

Yan, W., Montoya, C., Oilo, M., Ossa, A., Paranjpe, A., Zhang, H., \& Arola, D., 2017. Reduction in Fracture Resistance of the Root with Aging. J. Endod. 43, 1494-1498.

Zaslansky, P., Currey, J. D., \& Fleck, C., 2016. Learning from evolutionary optimisation: what are toughening mechanisms good for in dentine, a nonrepairing bone tissue? Bioinspir. Biomim. 11, 051003.

Zelic, K., Milovanovic, P., Rakocevic, Z., Askrabic, S., Potocnik, J., Popovic, M., \& Djuric, M., 2014. Nano-structural and compositional basis of devitalized tooth fragility. Dent. Mater. 30, 476-486.

Zelic, K., Vukicevic, A., Jovicic, G., Aleksandrovic, S., Filipovic, N., \& Djuric, M., 2015. Mechanical weakening of devitalized teeth: three-dimensional Finite Element Analysis and prediction of tooth fracture. Int. Endod. J. 48, 850-863. 
Table 1 - The test groups, chemical, heat treatments and physical tests

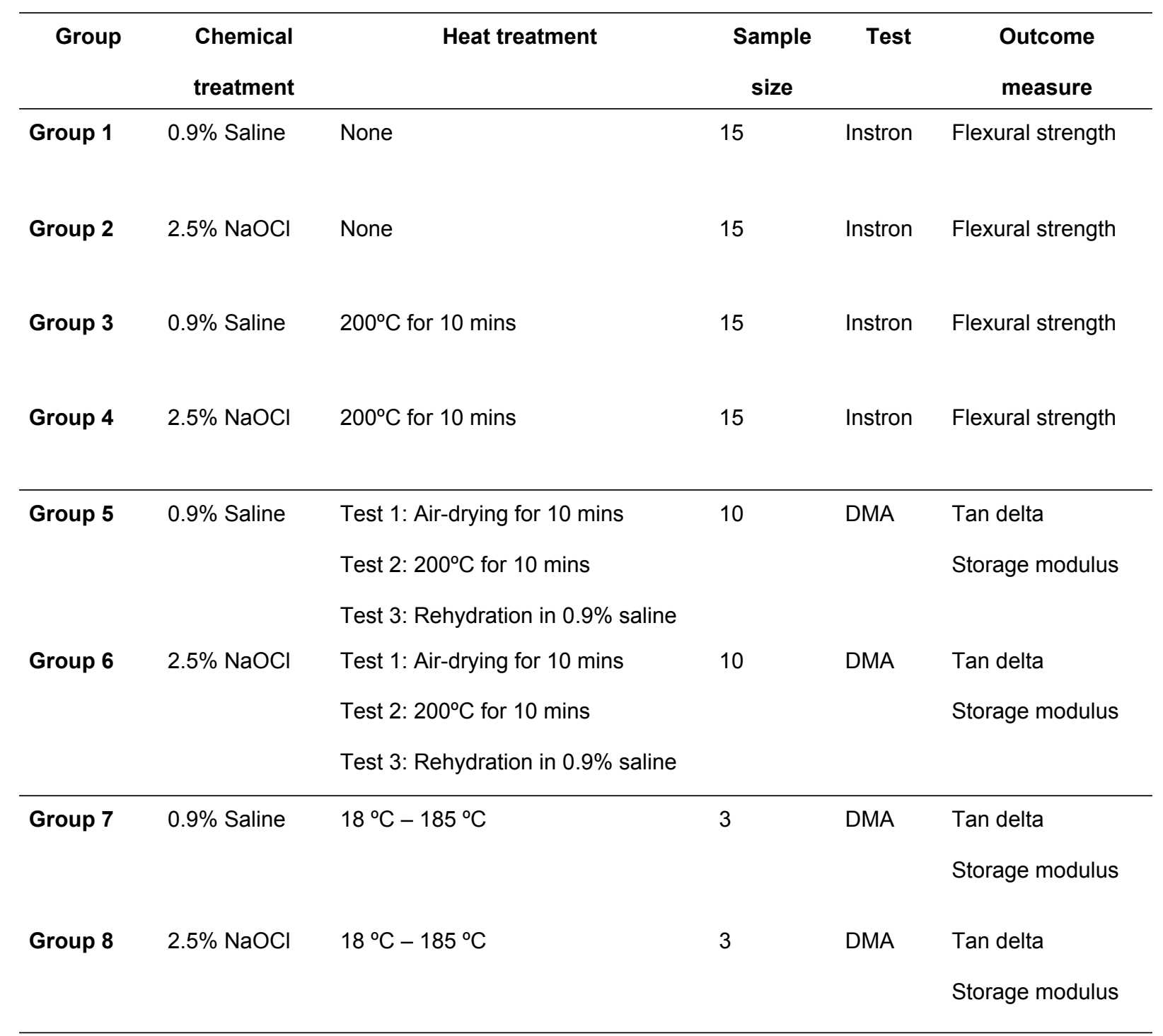


Table 2 - Mean $( \pm S D)$ flexural strength and maximum strain of dentine bars in groups 1-4 and the effects of sodium hypochlorite, and heat treatment

\begin{tabular}{|c|c|c|c|c|c|}
\hline Groups & $\mathbf{N}$ & \multicolumn{2}{|c|}{$\begin{array}{c}\text { Mean }( \pm S D) \\
\text { flexural strength } \\
(\mathrm{MPa})\end{array}$} & \multicolumn{2}{|c|}{$\begin{array}{c}\text { Mean }( \pm S D) \\
\text { maximum strain at fracture } \\
(\%)\end{array}$} \\
\hline Group 1 (Saline - no heat) & 15 & \multicolumn{2}{|c|}{$0.30 \pm 0.30$} & \multicolumn{2}{|c|}{$1.64 \pm 0.60$} \\
\hline Group 2 ( $\mathrm{NaOCl}$ - no heat) & 15 & \multicolumn{2}{|c|}{$0.18 \pm 0.04$} & \multicolumn{2}{|c|}{$1.02 \pm 0.41$} \\
\hline Group 3 (Saline $-200^{\circ} \mathrm{C}$ ) & 15 & \multicolumn{2}{|c|}{$0.22 \pm 0.06$} & \multicolumn{2}{|c|}{$1.66 \pm 0.76$} \\
\hline Group $4\left(\mathrm{NaOCl}-200^{\circ} \mathrm{C}\right)$ & 14 & \multicolumn{2}{|c|}{$0.31 \pm 0.34$} & \multicolumn{2}{|c|}{$1.79 \pm 1.25$} \\
\hline \multicolumn{6}{|l|}{ General Linear Models } \\
\hline Independent variables & df & $\mathbf{F}$ & $P$ value & $\mathbf{F}$ & $P$ value \\
\hline Heat $\left(200^{\circ} \mathrm{C}\right.$ vs room temperature $)$ & 1 & 0.17 & 0.6 & 3.54 & 0.07 \\
\hline $\mathrm{NaOCl}(\mathrm{NaOCl}$ vs Saline) & 1 & 0.08 & 0.8 & 1.36 & 0.2 \\
\hline Heat ${ }^{*} \mathrm{NaOCl}$ & 1 & 3.59 & 0.06 & 3.21 & 0.08 \\
\hline
\end{tabular}


Table 3 - Mean ( $\pm S D$ ) storage modulus and tan delta of dentine bars in groups 5 \& 6 , before heat treatment, after heat treatment and following rehydration in the saline (NB. Two bars in the saline group fractured during testing).

\begin{tabular}{|c|c|c|c|c|c|c|c|c|}
\hline \multirow[b]{2}{*}{ Group } & \multicolumn{4}{|c|}{ Mean storage modulus (GPa) } & \multicolumn{4}{|c|}{ Mean tan delta } \\
\hline & $\begin{array}{l}\text { Test } 1 \\
\text { No heat }\end{array}$ & $\begin{array}{l}\text { Test } 2 \\
200^{\circ} \mathrm{C} \text { for } 10 \\
\text { minutes }\end{array}$ & $\begin{array}{c}\text { Test } 3 \\
\text { Rehydration }\end{array}$ & $\begin{array}{c}\text { Repeated } \\
\text { ANOVA }\end{array}$ & $\begin{array}{l}\text { Test } 1 \\
\text { No heat }\end{array}$ & $\begin{array}{l}\text { Test } 2 \\
200^{\circ} \mathrm{C} \text { for } 10 \\
\text { minutes }\end{array}$ & $\begin{array}{c}\text { Test } 3 \\
\text { Rehydration }\end{array}$ & $\begin{array}{c}\text { Repeated } \\
\text { ANOVA }\end{array}$ \\
\hline $\begin{array}{l}\text { Group 5: Saline } \\
\qquad(n=8)\end{array}$ & $14.3 \pm 4.1$ & $15.9 \pm 4.3$ & $14.0 \pm 14.0$ & $P=0.06$ & $0.056 \pm 0.059$ & $0.054 \pm 0.005$ & $0.068 \pm 0.011$ & $P=0.0002$ \\
\hline $\begin{array}{l}\text { Pairwise comparisons of } \\
\text { marginal linear predictions }\end{array}$ & \multicolumn{4}{|c|}{$\begin{array}{l}\text { Test } 2 \text { vs } 1(P=0.06) \\
\text { Test } 3 \text { vs } 1(P=0.7) \\
\text { Test } 3 \text { vs } 2(P=0.03)\end{array}$} & \multicolumn{3}{|c|}{$\begin{array}{l}\text { Test } 2 \text { vs } 1(P=0.4) \\
\text { Test } 3 \text { vs } 1(P=0.001) \\
\text { Test } 3 \text { vs } 2(P<0.0001)\end{array}$} & \\
\hline $\begin{array}{c}\text { Group 6: } \mathrm{NaOCl} \\
(n=10)\end{array}$ & $16.3 \pm 7.3$ & $16.3 \pm 13.5$ & $14.9 \pm 8.3$ & $P=0.6$ & $0.059 \pm 0.007$ & $0.061 \pm 0.012$ & $0.068 \pm 0.013$ & $P=0.02$ \\
\hline $\begin{array}{l}\text { Pairwise comparisons of } \\
\text { marginal linear predictions }\end{array}$ & \multicolumn{4}{|c|}{$\begin{array}{l}\text { Test } 2 \text { vs } 1(P=1) \\
\text { Test } 3 \text { vs } 1(P=0.4) \\
\text { Test } 3 \text { vs } 2(P=0.4)\end{array}$} & \multicolumn{3}{|c|}{$\begin{array}{l}\text { Test } 2 \text { vs } 1(P=0.5) \\
\text { Test } 3 \text { vs } 1(P=0.007) \\
\text { Test } 3 \text { vs } 2(P=0.03)\end{array}$} & \\
\hline
\end{tabular}


Table 4 - Table with micro-Raman intensity means ( $\pm S D$ ) for groups $1-4$ and the effects of heat and $\mathrm{NaOCl}$ treatment on the apatite, carbonate, collagen peak intensity or ratio of mineral/collagen intensity.

\section{Dependent variables}

\begin{tabular}{|c|c|c|c|c|}
\hline Groups & $\begin{array}{c}\text { Apatite } \\
\left(960 \mathrm{~cm}^{-1}\right)\end{array}$ & $\begin{array}{l}\text { Carbonate } \\
\left(1072 \mathrm{~cm}^{-1}\right)\end{array}$ & $\begin{array}{l}\text { Collagen } \\
\left(1667 \mathrm{~cm}^{-1}\right)\end{array}$ & $\begin{array}{c}\text { Mineral/Collagen } \\
\text { Ratio }\end{array}$ \\
\hline Group 1 (Saline - no heat) & $1.52 \pm 0.17$ & $0.23 \pm 0.004$ & $0.15 \pm 0.02$ & $10.3 \pm 1.99$ \\
\hline Group 2 ( $\mathrm{NaOCl}$ - no heat) & $1.40 \pm 0.17$ & $0.26 \pm 0.02$ & $0.13 \pm 0.02$ & $11.1 \pm 2.43$ \\
\hline Group 3 (Saline - $200^{\circ} \mathrm{C}$ ) & $1.32 \pm 0.15$ & $0.23 \pm 0.02$ & $0.14 \pm 0.003$ & $10.0 \pm 0.05$ \\
\hline Group $4\left(\mathrm{NaOCl}-200^{\circ} \mathrm{C}\right)$ & $1.63 \pm 0.08$ & $0.26 \pm 0.01$ & $0.13 \pm 0.02$ & $12.6 \pm 1.87$ \\
\hline \multicolumn{5}{|l|}{ Two-way factorial ANOVA } \\
\hline Independent variables & P value & $P$ value & P value & $P$ value \\
\hline Heat $\left(200^{\circ} \mathrm{C}\right.$ vs room temperature) & 0.8 & 0.9 & 0.7 & 0.6 \\
\hline $\mathrm{NaOCl}(\mathrm{NaOCl}$ vs Saline) & 0.3 & 0.04 & 0.1 & 0.1 \\
\hline Heat* $\mathrm{NaOCl}$ & 0.04 & 0.9 & 0.5 & 0.4 \\
\hline
\end{tabular}

${ }^{*} \mathrm{P}$ values for Two-way factorial ANOVA for the effect each independent variable on the respective dependent variable in the same column 
Figure 1 - Changes in storage modulus and tan delta with temperature increase; saline group.

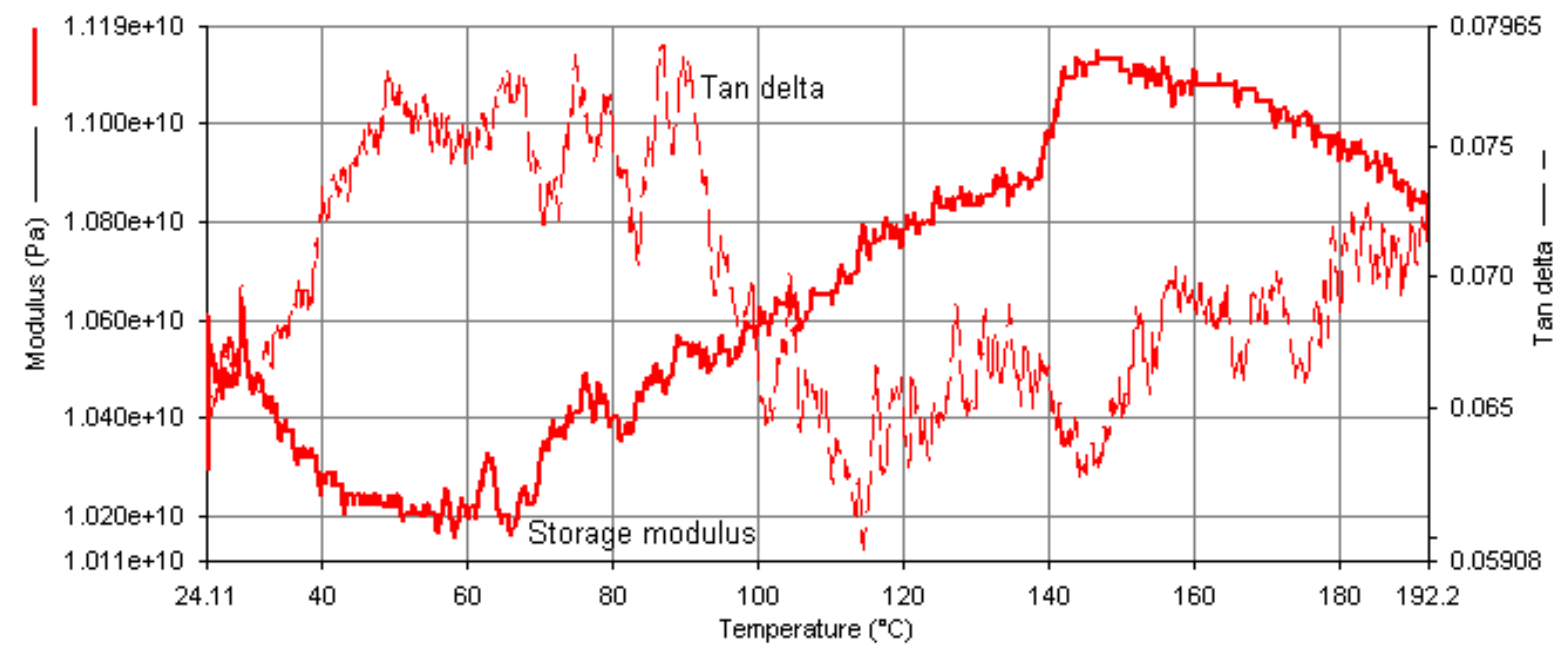


Figure 2 - Changes in storage modulus and tan delta with temperature increase; sodium hypochlorite group.
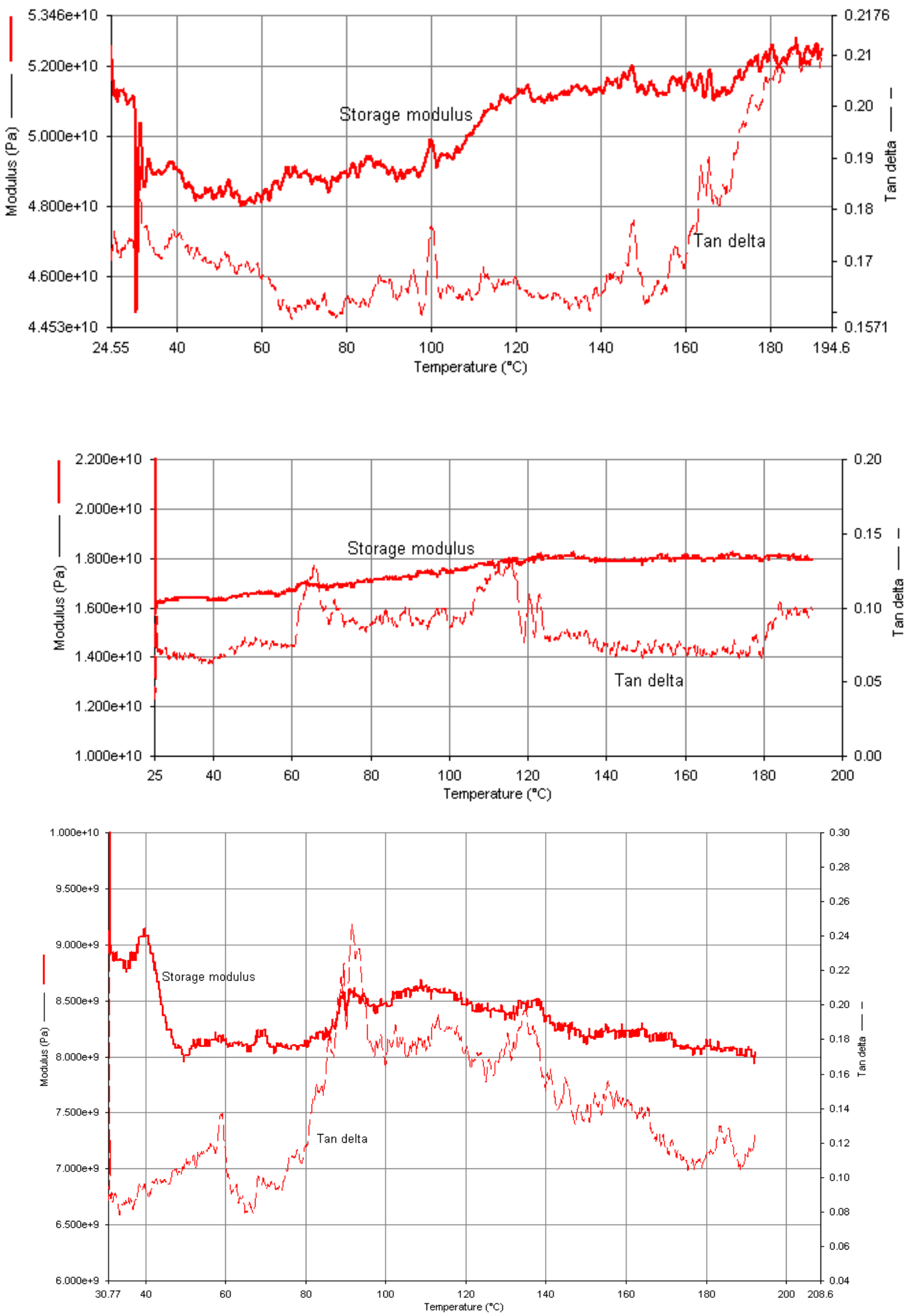
Figure 3 - Micro-Raman spectra of dentine from groups 1- $4\left(800-1750 \mathrm{~cm}^{-1}\right.$ region).

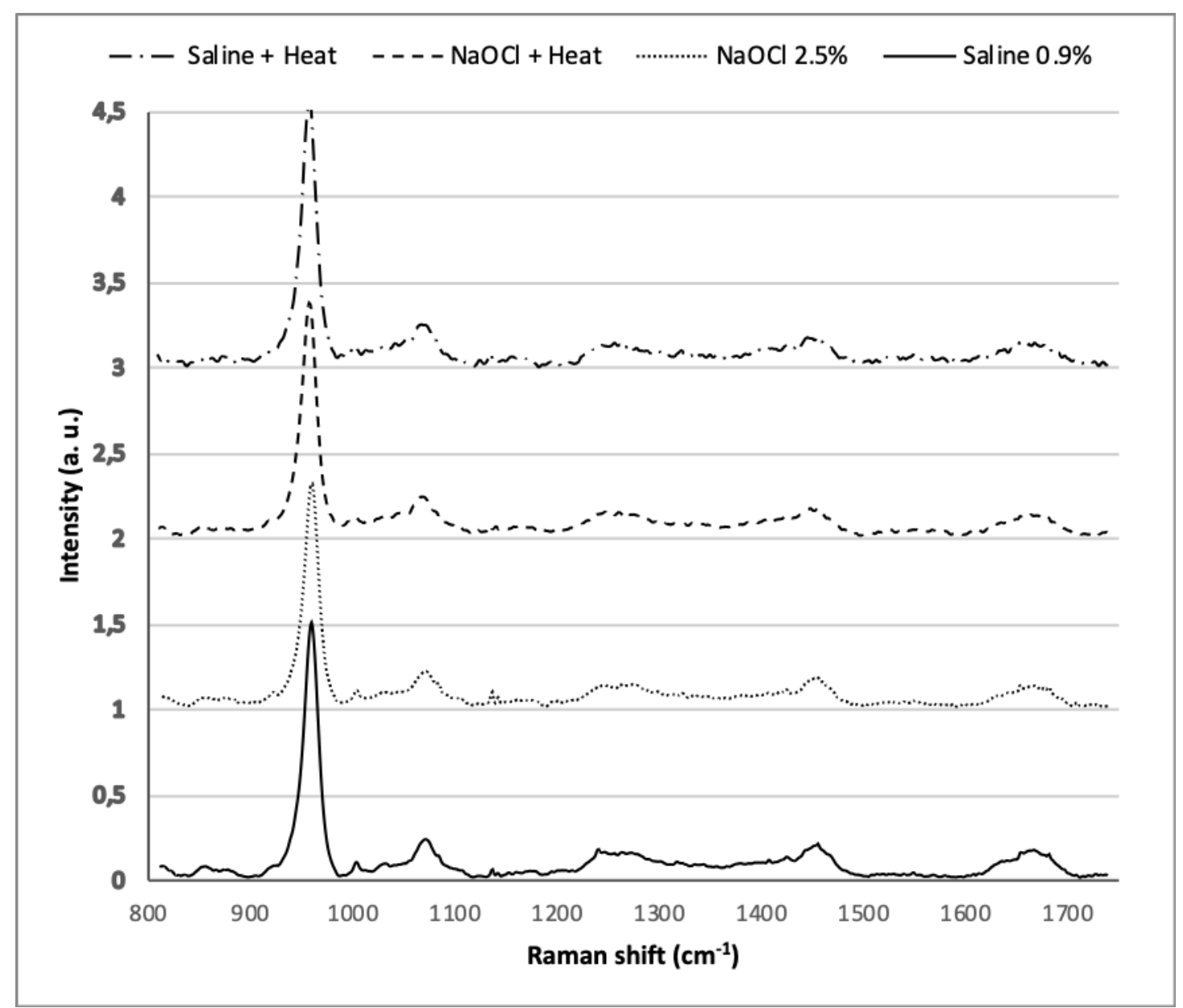




\section{AUTHOR DECLARATION}

We wish to confirm that there are no known conflicts of interest associated with this publication and there has been no significant financial support for this work that could have influenced its outcome.

We confirm that the manuscript has been read and approved by all named authors and that there are no other persons who satisfied the criteria for authorship but are not listed. We further confirm that the order of authors listed in the manuscript has been approved by all of us.

We confirm that we have given due consideration to the protection of intellectual property associated with this work and that there are no impediments to publication, including the timing of publication, with respect to intellectual property. In so doing we confirm that we have followed the regulations of our institutions concerning intellectual property.

We understand that the Corresponding Author is the sole contact for the Editorial process (including Editorial Manager and direct communications with the office). She is responsible for communicating with the other authors about progress, submissions of revisions and final approval of proofs. We confirm that we have provided a current, correct email address which is accessible by the Corresponding Author and which has been configured to accept email from: Karunanayake G: glen.karunanayake@unc.edu; Yuan-Ling Ng (corresponding author):y.ng@ucl.ac.uk; Knowles JC: j.knowles@ucl.ac.uk; Delgado AHS: ant.delgado94@gmail.com; Young AM: a.young@ucl.ac.uk; Gulabivala K: kishor.gulabivala@nhs.net; Nazhat SN: showan.nazhat@mcgill.ca.

\section{Signed by all authors as follows:}

